\title{
Blockade of Tumor Necrosis Factor-Alpha: A Role for Adalimumab in Neovascular Age-Related Macular Degeneration Refractory to Anti-Angiogenesis Therapy?
}

\author{
Beatriz Fernández-Vega ${ }^{a}$ Álvaro Fernández-Vega ${ }^{a}$ \\ Carlos Mario Rangel ${ }^{a, c}$ Javier Nicieza ${ }^{e} \quad$ Eva Villota-Deleu ${ }^{a}$ \\ José A. Vega ${ }^{a, b}$ Ronald M. Sanchez-Avilaa ${ }^{a, d}$ \\ ${ }^{a}$ Instituto Oftalmológico Fernández-Vega, and ${ }^{b}$ Departamento de Morfología y Biología

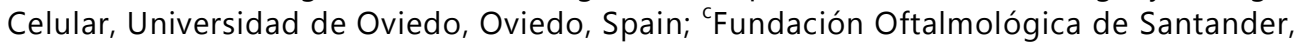 \\ FOSCAL, Floridablanca, Colombia; ${ }^{\mathrm{d}}$ Hospital Universitario Central de Asturias, Oviedo, and \\ ${ }^{\mathrm{e}}$ Hospital de Cabueñes, Gijón, Spain
}

\section{Key Words}

Anti-vascular endothelial growth factor - Tumor necrosis factor-alpha inhibitors .

Wet age-related macular degeneration

\begin{abstract}
Aims: To report a case of wet age-related macular degeneration (wet-AMD) refractory to intravitreal anti-vascular endothelial growth factor (anti-VEGF) therapy in a patient who showed visual and anatomical improvement and stabilization after starting a subcutaneous treatment course with adalimumab, an anti-tumor necrosis factor-alpha (TNF- $\alpha$ ) drug, for concomitant Crohn's disease. Methods: Observational case report of a female patient. Ophthalmological evaluation was performed by slit lamp and ophthalmoscopy (posterior pole and anterior segment). Best-corrected visual acuity (BCVA) was determined, and imaging was performed by fluorescein angiography, indocyanine green angiography, and optical coherence tomography (OCT). Intravitreal therapies used and treatment with anti-TNF- $\alpha$ were recorded. Results: A 64-year-old woman with wet-AMD was treated with fourteen intravitreal injections of ranibizumab $(0.5 \mathrm{mg})$ for a period of 40 months with intervals of 1-6 months.
\end{abstract}

\section{KARGER}


Fernández-Vega et al.: Blockade of Tumor Necrosis Factor-Alpha: A Role for Adalimumab in Neovascular AMD Refractory to Anti-Angiogenesis Therapy?

She initially showed a good visual and anatomical response to periodic anti-VEGF treatment but during check visits, anatomical and functional responses deteriorated. At the 40-month follow-up, the patient had developed Crohn's disease, and her rheumatologist started treatment with adalimumab (40 mg subcutaneously every 2 weeks). During the 25 months of treatment with adalimumab, the patient did not require any additional intravitreal anti-VEGF treatments because her BCVA, clinical, and OCT findings improved and remained stable. Conclusions: We described a case of a patient with wet-AMD refractory to anti-VEGF therapy, which clinically benefited from subcutaneous adalimumab therapy. Treatment with subcutaneous anti-TNF- $\alpha$ in combination with anti-VEGF therapy avoids the high cost and risks related to multiple intravitreal anti-VEGF injections with good functional and anatomic outcomes.

\author{
Published by S. Karger AG, Basel
}

\title{
Introduction
}

Age-related macular degeneration (AMD) is the principal cause of central visual loss in individuals over 55 years [1]. In neovascular AMD with choroidal neovascularization (CNV), damage to the outer retinal cells and retinal pigment epithelium (RPE) elicits a cascade of inflammatory and angiogenic responses that lead to neovascularization under the macula [2]. Vascular endothelial growth factors (VEGFs) are the most specific and crucial regulators of angiogenesis [3]. Ranibizumab, a high-affinity recombinant antigen-binding fragment (Fab) that neutralizes all isoforms of VEGF-A, blocks VEGF-A-induced angiogenesis, has been approved for intravitreal therapy for the treatment of neovascular AMD [4]. However, intravitreal therapies can bring rare but serious risks, such as endophthalmitis, vascular occlusions, crystalline lens injury, and increased intraocular pressure among others [5]. Tumor necrosis factor-alpha (TNF- $\alpha$ ) is the prototypical member of a family of cytokines that also include FasL, CD40L, and TRAIL. These cytokines are involved in proapoptosis, proinflammatory responses, differentiation, and cell activation [6]. The concentration of TNF- $\alpha$ is elevated in several rheumatic diseases, such as rheumatoid arthritis, ankylosing spondylitis, Crohn's disease, and psoriatic arthritis [7]. TNF- $\alpha$ seems to participate in the pathogenesis of multiple types of uveitis [8]. Inflammatory cytokines, including interleukin 1 beta, interferon gamma, and TNF- $\alpha$, increase the secretion of VEGF in RPE cells and choroidal fibroblasts [9]. TNF- $\alpha$ receptors are expressed in many cell types in the retina and choroid plexus, including the RPE, Müller cells, and choroidal vascular cells $[2,10,11]$. Systemic and intravitreal injections of anti-TNF- $\alpha$ administered alone or in combination with anti-VEGF drugs have been used to treat multiple eye diseases such as uveitis [12-14], neovascular AMD [15-19], diabetic macular edema (DME) [20-23], cystoid macular edema due to cataract surgery [22, 23], branch retinal vein occlusion [23], and central retinal vein occlusion (CRVO) [23]. The clinical results of these applications have been variable. Markomichelakis et al. [15] reported three cases of regression of CNV secondary to AMD in patients receiving systemic treatment with infliximab, an anti-TNF- $\alpha$ drug for inflammatory arthritis. All 3 patients had an increase in visual acuity (VA) after treatment. This sets a precedent for the use of anti-TNF- $\alpha$ in these types of ophthalmic patients. Here, we describe a patient with neovascular AMD who required multiple intravitreal injections of ranibizumab to maintain a precarious clinical stability, but for whom there was clear deterioration during 40 months of follow-up. However, after administration of subcutaneous adalimumab (Humira ${ }^{\circledR}$ ) injections for concurrent Crohn's disease, her vision and the clinical appearance of her neovascular AMD improved significantly during the next 25 months. 
Fernández-Vega et al.: Blockade of Tumor Necrosis Factor-Alpha: A Role for Adalimumab in Neovascular AMD Refractory to Anti-Angiogenesis Therapy?

\section{Case Report}

In August 2008, a 64-year-old woman with no known systemic diseases visited the Fernandez-Vega Ophthalmological Institute, Oviedo, Spain, with metamorphopsia and a decrease of central vision in her left eye that had occurred over the preceding year. The bestcorrected visual acuity (BCVA) was 0.3 in the affected eye, and slit-lamp examination showed no alteration in the anterior segment. The intraocular pressure was $16 \mathrm{~mm} \mathrm{Hg}$ in both eyes. Dilated fundus examination showed subretinal yellowish deposits and drusen in the macular area in both eyes. The deposits were associated with pigmentary changes in her left eye (fig. 1a, left). Fluorescein angiography showed no significant alterations in the right eye, but in the left eye, there was early macular hyperfluorescence that increased in the last stages of the angiography (fig. 1a, middle). Indocyanine green angiography showed central hyperfluorescence throughout the examination (fig. 1a, right). Optical coherence tomography (OCT) of the right eye demonstrated only subfoveal drusen and some RPE disruption, whereas OCT of the left eye showed a macular central thickness of $237 \mu \mathrm{m}$ and intraretinal and subretinal fluid associated with shallow RPE detachment and subfoveal deposits and drusen (fig. 1b). The patient was diagnosed with dry AMD in her right eye and wet-AMD in her left eye. We started treatment on the left eye with intravitreal injections of ranibizumab (0.5 mg once a month for 3 months). Subsequent booster injections ( $0.5 \mathrm{mg}$ ) were given according to the ophthalmological findings in follow-up visits in a pro re nata treatment modality. The right eye was evaluated at each visit to assess the stability of the dry AMD. After the initial doses of ranibizumab (August-October 2008) in her left eye, the patient experienced clinical improvement with the disappearance of the subretinal fluid (fig. 2), and her BVCA improved to 0.9. However, during the following 40 months, she experienced decompensation of the neovascular AMD (fig. $2 b, d, f$ ), requiring rescue with eleven additional injections of ranibizumab ( $0.5 \mathrm{mg}$ intravitreal) with intervals of 1-6 months. Improvement was maintained with BVCA ranging between 0.4 and 0.8 . We decided not to switch to another antiangiogenic drug such as bevacizumab or aflibercept throughout the monitoring period because we believed that with ranibizumab the clinical response was quite good. In December 2011, the patient was diagnosed to have Crohn's disease, and began treatment with adalimumab (Humira ${ }^{\circledR}$ ) (40 mg subcutaneously every 2 weeks) ordered by her rheumatologist (Hospital Universitario Central de Asturias, Oviedo, Spain), which is the standard treatment for this disease. For the next 25 months after the initiation of adalimumab treatment, the patient did not require any new injections of ranibizumab to maintain vision and clinical stability. Vision in her left eye maintained a VA of 0.7 from the first month after initiation of therapy with adalimumab, and no neovascular AMD activity was apparent (fig. 3a-c). The patient only required an annual booster injection of ranibizumab in 2014 and 2015 to maintain clinical stability associated with adalimumab.

\section{Discussion}

TNF- $\alpha$ has been implicated in the pathogenesis of inflammatory, edematous, neovascular, and neurodegenerative diseases of the eye [24]. Several anti-TNF- $\alpha$ drugs are currently available for the therapeutic management of these conditions, including infliximab (Remicade $^{\circledR}$ ), adalimumab (Humira ${ }^{\circledR}$ ), etanercept (Enbrel ${ }^{\circledR}$ ), certolizumab pegol (Cimzia ${ }^{\circledR}$ ), and golimumab (Simponi ${ }^{\circledR}$ ) [6]. Since introduction, anti-TNF- $\alpha$ drugs have been used by ophthalmologists to treat several ocular diseases 'off-label', i.e., out of the indications approved by a regulatory agency but which can be used in the context of compassionate therapy [6] 
Fernández-Vega et al.: Blockade of Tumor Necrosis Factor-Alpha: A Role for Adalimumab in Neovascular AMD Refractory to Anti-Angiogenesis Therapy?

(see Appendix 1). The anti-inflammatory effects of TNF- $\alpha$ inhibitors make these agents an obvious therapeutic alternative for treating noninfectious ocular inflammation, especially when conventional therapy has failed or carries the risk of adverse effects with chronic use [12-14]. One study reported positive outcomes without any ocular adverse events after intravitreal administration of infliximab in patients with chronic persistent noninfectious uveitis [13]. Another study reported that a single intravitreal injection of $1.0 \mathrm{mg} / 0.05 \mathrm{ml}$ of infliximab controlled intraocular inflammation among patients with relapsing posterior uveitis associated with Behçet's disease [14]. Considering the inflammatory process underlying the development of AMD, anti-TNF- $\alpha$ therapy could potentially offer benefits for the treatment of this disease. In the present case, we believe that the observed BVCA and anatomical improvements can be attributed to subcutaneous systemic adalimumab administration as an anti-VEGF therapy adjuvant. This conclusion is supported by the fact that the patient did not attain optimal responses to the prior intravitreal ranibizumab injections, even after 14 doses. Several case studies have described treatment of patients with neovascular AMD using intravitreal anti-TNF- $\alpha$ therapy, albeit with variable outcomes [15-19]. However, to date, there have been no published studies of subcutaneous administration of adalimumab in patients with neovascular AMD. One study reported regression of three cases of CNV secondary to AMD in patients receiving intravenous administration of infliximab for inflammatory arthritis [15]. All three cases had an increase in VA. Arias et al. [16] conducted a prospective interventional trial of 4 patients with neovascular AMD that was refractory to antiVEGF agents. Intravitreal infliximab was administered at a dosage of $2 \mathrm{mg}$ but produced no visual or anatomical benefit. Furthermore, 2 of the patients in that study developed a severe intraocular inflammatory reaction. On the other hand, Theodossiadis et al. [18] described 3 patients with improved VA after treatment with intravitreal infliximab for neovascular AMD. Giganti et al. [19] used low-dose intravitreal infliximab $(0.5 \mathrm{mg} / 0.05 \mathrm{ml})$ to treat 2 patients with neovascular AMD and 2 patients with DME. Pretreatment of all 4 patients included antiVEGF therapy, and/or laser coagulation, and/or photodynamic therapy. The VA in only 1 patient with neovascular AMD improved. The other patients showed decreases in VA and developed intraocular inflammation. Wu et al. [20] conducted a multicenter and retrospective study in patients with DME. They treated 39 eyes with either intravitreal adalimumab (2 $\mathrm{mg} / 0.1 \mathrm{ml}$ ) or intravitreal infliximab $(1 \mathrm{mg} / 0.05 \mathrm{ml}$ or $2 \mathrm{mg} / 0.1 \mathrm{ml})$. All patients had received at least three injections of VEGF inhibitors prior to receiving the TNF- $\alpha$ inhibitor. VA did not increase significantly in either the adalimumab or the 1-mg infliximab group after 3 months. In the 2-mg infliximab group, VA actually deteriorated. Macular thickness decreased in both infliximab groups but was unchanged in the adalimumab group. In the 2-mg infliximab group, $42 \%$ of patients developed severe uveitis that resolved with medical therapy and surgery. Sfikakis et al. [21] used intravenous infliximab to treat 11 patients with AMD that was refractory to laser treatment. They observed marked VA improvement in 8 eyes. A descriptive study found that in seven cases of refractory pseudophakic cystoid macular edema, a single intravitreal injection of infliximab $(1.0 \mathrm{mg} / 0.10 \mathrm{ml})$ produced improvement of VA after 6 months [22]. In all cases, there was no intraocular inflammation. Several studies have investigated the potential role of TNF- $\alpha$ in the pathogenesis of eye diseases. Yoshimura et al. [25] collected vitreous specimens from the eyes of patients with diabetic retinopathy, CRVO, rhegmatogenous retinal detachment, and DME. They did not find elevated vitreous concentrations of TNF- $\alpha$ in any of these specimens. Suzuki et al. [26] analyzed the expression of cytokines in vitreous fluid and found a higher concentration of TNF- $\alpha$ in patients with CRVO than in patients with diabetic retinopathy. These studies do not support the hypothesis that TNF- $\alpha$ plays a major role in primary noninflammatory retinal diseases $[25,26]$; however, the choroid plexus or retina themselves might be the locus of increased TNF- $\alpha$ concentration, 
Fernández-Vega et al.: Blockade of Tumor Necrosis Factor-Alpha: A Role for Adalimumab in Neovascular AMD Refractory to Anti-Angiogenesis Therapy?

rather than the vitreous body [6]. In view of these studies [20-22], it is not surprising that the results obtained following intravitreal administration of TNF- $\alpha$ inhibitors are so heterogeneous [6]. Intravitreal injection of infliximab could be effective for severe intraocular inflammation, but it does not appear to benefit patients with refractory AMD or partially responsive neovascular AMD. Nevertheless, infliximab can be of some benefit in cases of persistent noninfectious posterior uveitis and refractory pseudophakic cystoid macular edema [27]. Intravitreal injections of adalimumab do not appear to benefit patients with dry AMD or neovascular AMD. Intravitreal administration of adalimumab and bevacizumab in combination might be effective in the management of patients with partially responsive neovascular AMD and macular edema of various etiologies [27]. Nevertheless, further preclinical and clinical studies are necessary to obtain firm conclusions regarding the use of intravitreal anti-TNF- $\alpha$ drugs with anti-VEGF drugs in the management of retinal diseases. To our knowledge, this is the first report of recurrent wet-AMD that improved following subcutaneous administration of an anti-TNF- $\alpha$ drug, adalimumab, for the treatment of an associated systemic rheumatic disease. These findings are very important because the use of this drug could be beneficial for the treatment of neovascular AMD in selected patients, while avoiding both the high cost and the risks related to repeated intravitreal injections of anti-VEGF agents. Future clinical studies could determine if patients with wet-AMD but without rheumatic diseases would benefit from subcutaneous adalimumab anti-VEGF in association with intravitreal anti-VEGF.

\section{Statement of Ethics}

This study was done according to the Declaration of Helsinki after written patient consent.

\section{Disclosure Statement}

There is no financial support from any organization. None of the authors has any financial/conflicting interests to disclose.

\section{Appendix 1}

Guideline on compassionate use of medicinal products, pursuant to Article 83 of Regulation (EC) No. 726/2004 (doc ref: EMEA/27170/2006). London: European Medicines Agency; 2007. Available at: http://www.ema.europa.eu/docs/en_GB/document_library/ Regulatory_and_procedural_guideline/2009/10/WC500004075.pdf (accessed January 20, 2011).

\section{References}

1 Bressler NM, Bressler SB, Fine SL: Age-related macular degeneration. Surv Ophthalmol 1988;32:375-413.

-2 de Oliveira Dias JR, Rodrigues EB, Maia M, Magalhaes O Jr, Penha FM, Farah ME: Cytokines in neovascular age-related macular degeneration: fundamentals of targeted combination therapy. Br J Ophthalmol 2011;95:1631-1637. 
Fernández-Vega et al.: Blockade of Tumor Necrosis Factor-Alpha: A Role for Adalimumab in Neovascular AMD Refractory to Anti-Angiogenesis Therapy?

3 Kliffen M, Sharma HS, Mooy CM, Kerkvliet S, de Jong PT: Increased expression of angiogenic growth factors in age-related maculopathy. Br J Ophthalmol 1997;81:154-162.

-4 Ferrara N, Damico L, Shams N, Lowman H, Kim R: Development of ranibizumab, an anti-vascular endothelial growth factor antigen binding fragment, as therapy for neovascular age-related macular degeneration. Retina 2006;26:859-870.

5 Tolentino M: Systemic and ocular safety of intravitreal anti-VEGF therapies for ocular neovascular disease. Surv Ophthalmol 2011;56:95-113.

-6 Mirshahi A, Hoehn R, Lorenz K, Kramann C, Baatz H: Anti-tumor necrosis factor alpha for retinal diseases: current knowledge and future concepts. J Ophthalmic Vis Res 2012;7:39-44.

7 McDermott MF: TNF and TNFR biology in health and disease. Cell Mol Biol (Noisy-le-grand) 2001;47:619635.

8 Cordero-Coma M, Sobrin L: Anti-tumor necrosis factor-alpha therapy in uveitis. Surv Ophthalmol 2015;60:575-589.

-9 Nagineni CN, Kommineni VK, William A, Detrick B, Hooks JJ: Regulation of VEGF expression in human retinal cells by cytokines: implications for the role of inflammation in age-related macular degeneration. J Cell Physiol 2012;227:116-126.

10 Majka S, McGuire PG, Das A: Regulation of matrix metalloproteinase expression by tumor necrosis factor in a murine model of retinal neovascularization. Invest Ophthalmol Vis Sci 2002;43:260-266.

11 Cousins SW, Espinosa-Heidmann DG, Csaky KG: Monocyte activation in patients with age-related macular degeneration: a biomarker of risk for choroidal neovascularization? Arch Ophthalmol 2004;122:1013-1018.

-12 Diaz-Llopis M, Garcia-Delpech S, Salom D, Udaondo P, Hernandez-Garfella M, Bosch-Morell F, et al: Adalimumab therapy for refractory uveitis: a pilot study. J Ocul Pharmacol Ther 2008;24:351-361.

13 Farvardin M, Afarid M, Shahrzad S: Long-term effects of intravitreal infliximab for treatment of sightthreatening chronic noninfectious uveitis. J Ocul Pharmacol Ther 2012;28:628-631.

14 Markomichelakis N, Delicha E, Masselos S, Sfikakis PP: Intravitreal infliximab for sight-threatening relapsing uveitis in Behcet disease: a pilot study in 15 patients. Am J Ophthalmol 2012;154:534-541 e1.

15 Markomichelakis NN, Theodossiadis PG, Sfikakis PP: Regression of neovascular age-related macular degeneration following infliximab therapy. Am J Ophthalmol 2005;139:537-540.

-16 Arias L, Caminal JM, Badia MB, Rubio MJ, Catala J, Pujol O: Intravitreal infliximab in patients with macular degeneration who are nonresponders to antivascular endothelial growth factor therapy. Retina 2010;30:1601-1608.

17 Wu L, Arevalo JF, Hernandez-Bogantes E, Regatieri CV, Roca JA, Farah ME: Intravitreal tumor necrosis factor-alpha inhibitors for neovascular age-related macular degeneration suboptimally responsive to antivascular endothelial growth factor agents: a pilot study from the Pan American Collaborative Retina Study Group. J Ocul Pharmacol Ther 2013;29:366-371.

18 Theodossiadis PG, Liarakos VS, Sfikakis PP, Vergados IA, Theodossiadis GP: Intravitreal administration of the anti-tumor necrosis factor agent infliximab for neovascular age-related macular degeneration. Am J Ophthalmol 2009;147:825-830, 830 e1.

19 Giganti M, Beer PM, Lemanski N, Hartman C, Schartman J, Falk N: Adverse events after intravitreal infliximab (Remicade). Retina 2010;30:71-80.

20 Wu L, Hernandez-Bogantes E, Roca JA, Arevalo JF, Barraza K, Lasave AF: intravitreal tumor necrosis factor inhibitors in the treatment of refractory diabetic macular edema: a pilot study from the Pan-American Collaborative Retina Study Group. Retina 2011;31:298-303.

21 Sfikakis PP, Grigoropoulos V, Emfietzoglou I, Theodossiadis G, Tentolouris N, Delicha E, et al: Infliximab for diabetic macular edema refractory to laser photocoagulation: a randomized, double-blind, placebocontrolled, crossover, 32-week study. Diabetes Care 2010;33:1523-1528.

-22 Wu L, Arevalo JF, Hernandez-Bogantes E, Roca JA: Intravitreal infliximab for refractory pseudophakic cystoid macular edema: results of the Pan-American Collaborative Retina Study Group. Int Ophthalmol 2012;32:235-243.

23 Arevalo JF, Serrano MA, Wu L: Combined inhibition of tumor necrosis factor (TNF) and vascular endothelial growth factor (VEGF) for the treatment of macular edema of various etiologies: a short-term pilot study. Eye (Lond) 2013;27:569-571.

24 Rodrigues EB, Farah ME, Maia M, Penha FM, Regatieri C, Melo GB, et al: Therapeutic monoclonal antibodies in ophthalmology. Prog Retin Eye Res 2009;28:117-144.

25 Yoshimura T, Sonoda KH, Sugahara M, Mochizuki Y, Enaida H, Oshima Y, et al: Comprehensive analysis of inflammatory immune mediators in vitreoretinal diseases. PLoS One 2009;4:e8158.

26 Suzuki Y, Nakazawa M, Suzuki K, Yamazaki H, Miyagawa Y: Expression profiles of cytokines and chemokines in vitreous fluid in diabetic retinopathy and central retinal vein occlusion. Jpn J Ophthalmol 2011;55:256263.

-27 Pascual-Camps I, Hernandez-Martinez P, Monje-Fernandez L, Dolz-Marco R, Gallego-Pinazo R, Wu L, et al: Update on intravitreal anti-tumor necrosis factor alpha therapies for ocular disorders. J Ophthalmic Inflamm Infect 2014;4:26. 


\section{Case Reports in \\ Ophthalmology}

\begin{tabular}{l|l}
\hline Case Rep Ophthalmol 2016;7:154-162 \\
\hline DOI: 10.1159/000445102 & $\begin{array}{l}\text { ○ 2016 The Author(s). Published by S. Karger AG, Basel } \\
\text { www.karger.com/cop }\end{array}$ \\
\hline
\end{tabular}
www.karger.com/cop

Fernández-Vega et al.: Blockade of Tumor Necrosis Factor-Alpha: A Role for Adalimumab in Neovascular AMD Refractory to Anti-Angiogenesis Therapy?

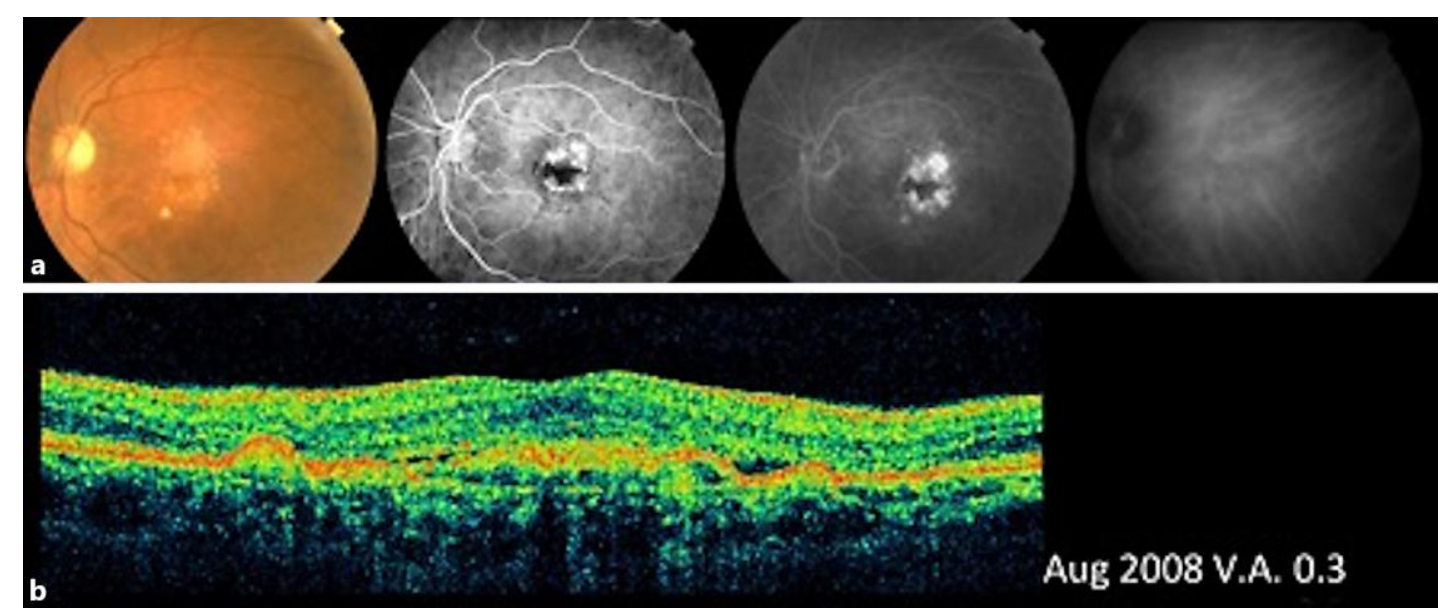

Fig. 1. Features of neovascular AMD in the patient's left eye at diagnosis. a Left: fundus photograph of the left eye showing subretinal confluent drusen in the macular area. Center-left: fluorescein angiography showing macular hyperfluorescence in the early stages (center-right) that increases in the late stages. Right: indocyanine green angiography showing late hyperfluorescence. $\mathbf{b}$ OCT of the left eye showing RPE detachment with intraretinal, subretinal, and sub-RPE fluid. 


\section{Case Reports in \\ Ophthalmology}

\begin{tabular}{l|l}
\hline Case Rep Ophthalmol 2016;7:154-162 \\
\hline DOI: 10.1159/000445102 & $\begin{array}{l}\text { ○ 2016 The Author(s). Published by S. Karger AG, Basel } \\
\text { www.karger.com/cop }\end{array}$ \\
\hline
\end{tabular}

Fernández-Vega et al.: Blockade of Tumor Necrosis Factor-Alpha: A Role for Adalimumab in Neovascular AMD Refractory to Anti-Angiogenesis Therapy?

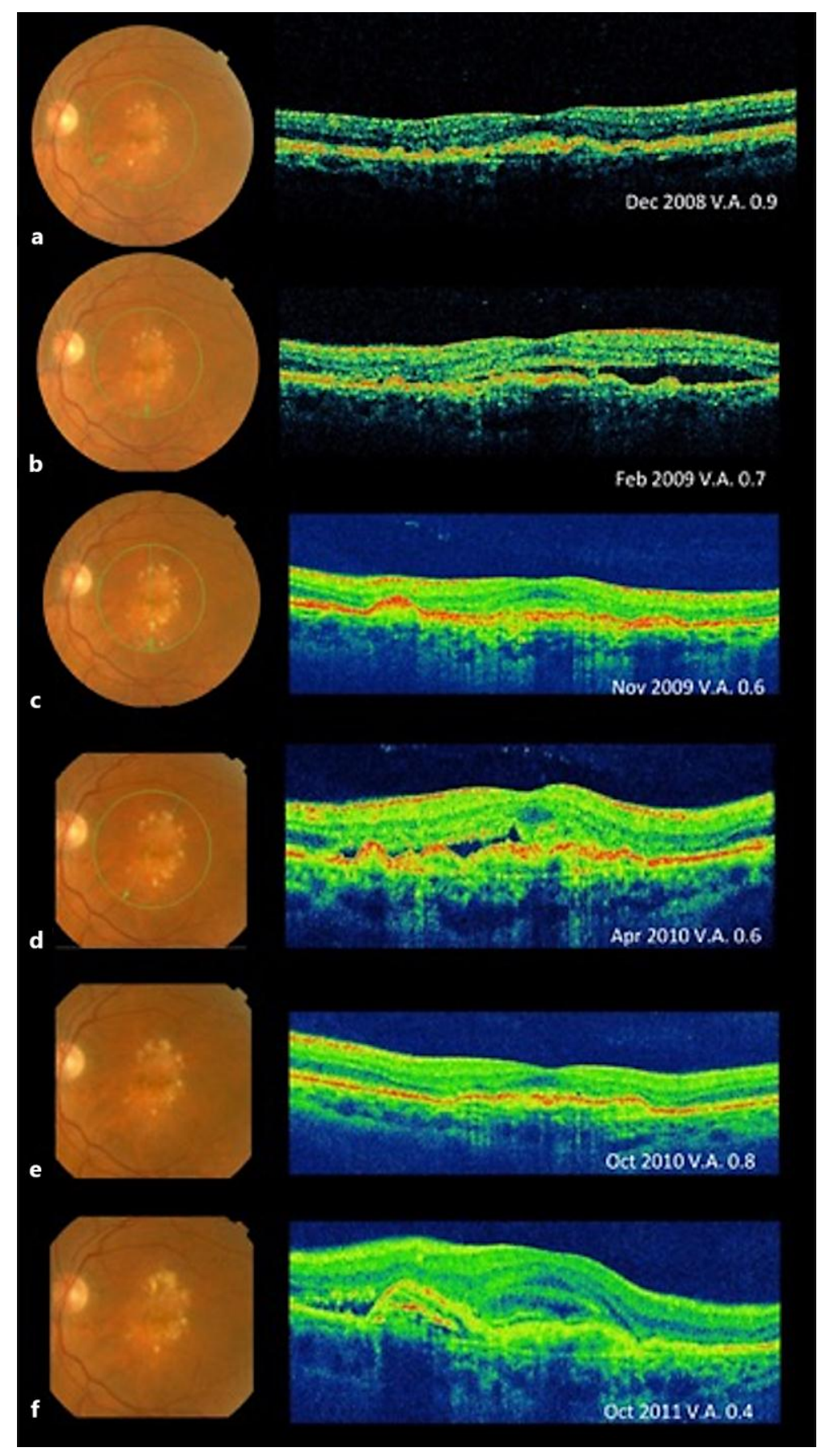

Fig. 2. Changes in the macula and VA while treated with intravitreal ranibizumab alone. a December 2008: fundus photography and OCT of the left eye after three doses of intravitreal ranibizumab. OCT showing drusen, but with marked improvement in the previously observed intraretinal, subretinal, and sub-RPE fluid. b February 2009: fundus photography and OCT of the left eye showing subretinal fluid and RPE detachment due to reactivation of CNV. c-f Fundus photography and OCT showing successive reactivations and improvements after the completion of the corresponding treatments in a pro re nata basis of treatment with ranibizumab during 40 months of follow-up. OCT in panels $\mathbf{b}$, $\mathbf{d}$ and $\mathbf{f}$ showing the recurrences of intraretinal, subretinal, and sub-RPE fluid. OCT in panels a, $\mathbf{c}$ and e showing the subsequent improvement after anti-VEGF treatment. 


\section{Case Reports in Ophthalmology}

\begin{tabular}{l|l}
\hline Case Rep Ophthalmol 2016;7:154-162 \\
\hline DOI: 10.1159/000445102 & $\begin{array}{l}\text { ○ 2016 The Author(s). Published by S. Karger AG, Basel } \\
\text { www.karger.com/cop }\end{array}$ \\
\hline
\end{tabular}

Fernández-Vega et al.: Blockade of Tumor Necrosis Factor-Alpha: A Role for Adalimumab in Neovascular AMD Refractory to Anti-Angiogenesis Therapy?

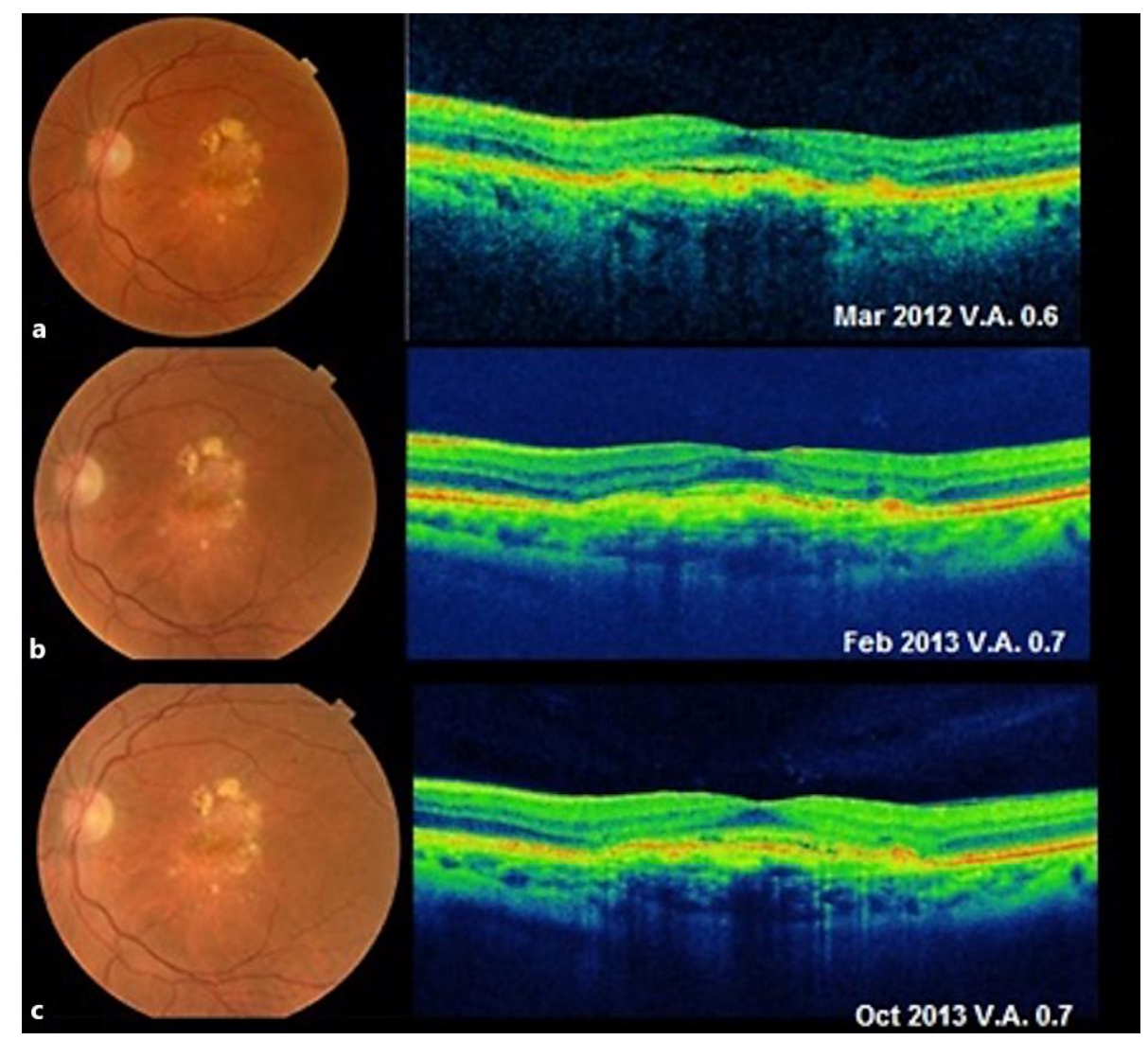

Fig. 3. AMD improvement with subcutaneous adalimumab treatment (March 2012-October 2014). VA, OCT, and clinical findings remained stable without any additional anti-VEGF therapy after starting subcutaneous adalimumab therapy. 